\title{
Impact of environmental temperature and relative humidity on spread of COVID-19 infection in India: A cross-sectional time-series analysis
}

\author{
Ansuman Panigrahi ( $\nabla$ dr.ansuman3@gmail.com ) \\ Kalinga Institute of Medical Sciences \\ Ipsa Mohapatra \\ Kalinga Institute of Medical Sciences
}

S. Suneeti Kanyari

Kalinga Institute of Medical Sciences

Sabita Maharana

Kalinga Institute of Medical Sciences

Madhulita Panigrahi

Independent Researcher

\section{Research Article}

Keywords: COVID-19, Temperature, Relative humidity, Malaria endemicity, Percent increase

Posted Date: October 5th, 2020

DOI: https://doi.org/10.21203/rs.3.rs-84876/v1

License: (c) (i) This work is licensed under a Creative Commons Attribution 4.0 International License. Read Full License 


\section{Abstract}

Purpose: Coronavirus disease 2019 (COVID-19) has become a serious public health problem worldwide. This study sought to examine the associations of daily average temperature (AT) and relative humidity $(\mathrm{ARH})$ with the percent increase in COVID-19 cases.

Methods: Daily confirmed cases and meteorological factors in 38 districts of India were collected between $1^{\text {st }}$ April 2020 to $30^{\text {th }}$ April 2020. Taking a 5-day time lag of average values of the variables and multiple days-samples, we ran multiple models and performed appropriate hypothesis tests to decide the single preferred model for each sample data. Suitable fixed effects (FE) and random effects (RE) models with cluster-robust standard errors were applied to quantify the district-specific associations between meteorological variables and COVID-19 cases.

Results: All FE models revealed that every one-degree rise in AT led to a decrease in 3.909 points (on average) in percent increase in COVID-19 cases. All RE models showed that with one unit increase in the malaria annual parasite index, there was a significant increase in 10.835 points (on average) in percent increase in COVID-19 cases. In both FE and RE models, ARH was found to be negatively associated with percent increase in COVID-19 cases, although in half of these models the association was statistically insignificant.

Conclusion: Our results indicate that mean temperature, mean relative humidity, and malaria endemicity might have an essential role in the stability and transmissibility of the 2019 novel coronavirus.

\section{Introduction}

Coronavirus disease 2019 (COVID-19) is caused by the new coronavirus called 2019-nCoV that was first identified in Wuhan city of China (Chen et al. 2020; Ghinai et al. 2020). Subsequently, it has spread to other regions of China and many other countries of the world and now it has become a serious public health problem worldwide (Sohrabi et al. 2020; Xu et al. 2020). COVID-19 is characterized by fever, cough, breathlessness, myalgia, pneumonia, and may cause progressive respiratory failure and death. On $30^{\text {th }}$ January 2020, India's first case of COVID-19 was confirmed in the state of Kerala and on $24^{\text {th }}$ March 2020, the Government of India initiated nationwide strict lockdown measures such as restriction of movement of the entire population of India, restriction of mass gatherings, closure of institutions, social distancing, and other quarantine methods to prevent against the COVID-19 pandemic in India. As of $30^{\text {th }}$ April 2020, data have shown that approximately 33,000 confirmed cases were identified and over 1100 deaths in the whole of India.

Earlier studies have demonstrated that COVID-19 is transmitted from person to person through direct contact or droplets (Chan et al. 2020; Lai et al. 2020; Li et al. 2020). Also, various studies have pointed to the role of climatic conditions like ambient temperature and humidity on the transmission and survival of 2019-nCoV (Gupta 2020; Harmooshi et al. 2020; Wang et al. 2020; Xie and Zhu 2020). To our knowledge, 
this is the first study in India in which we sought to explore the effect of environmental temperature and humidity on the spread of this novel coronavirus. To provide useful implications for policymakers and the public, our paper aimed to examine the relationship of daily average air temperature (AT) and relative humidity (ARH) with the percent increase in COVID-19 cases in different districts of India. We also assessed the effect of other covariates like daily average air pressure, daily average wind speed, latitude, longitude, BCG vaccination rate, Polio vaccination rate, and malaria endemicity on the spread of the 2019 novel coronavirus.

\section{Materials And Methods}

Study area and data collection:

Our study included panel data of 950 observations from 38 districts of 22 states that covered the majority of the Indian mainland ( $11^{0}$ to $35^{\circ}$ north latitude and $73^{0}$ to $93^{0}$ east longitude). The dataset including daily confirmed cases for all the districts of India was collected from the website by "GRAM India's data unlocked by How India Lives (https://howindialives.com/gram/coronadistricts/) for during April 2020. We chose the month of April as our study period as, during this period, lockdown measures were strictly followed across all the states of India which could have minimized the potential inclusion of imported cases to a particular district from another. We took a five-day incubation period between exposure and symptoms as estimated in previous studies (Lauer et al. 2020; Li et al. 2020). All the Indian districts that had at least one confirmed case on $6^{\text {th }}$ April and $\geq 20$ cases on $30^{\text {th }}$ April were included in our study. Meteorological information regarding daily average air temperature, daily average air pressure, daily average relative humidity, and daily average wind speed of each district during the same study period was acquired from the website (https://darksky.net/forecast). We took the average of hourly values of the meteorological variables from 8:00 a.m. to 8:00 p.m. Also, the latest data regarding latitude, longitude, BCG vaccination rate, Polio vaccination rate, and malaria annual parasite indices for each district were retrieved using publicly accessible websites (http://earth.google.com, http://rchiips.org/NFHS, http://nvbdcp.gov.in).

Statistical analysis:

Before the analysis of our panel data, we checked several assumptions for ordinary least squares (OLS) about the data. There was presence of heteroscedasticity and one extreme data point that was influential in the regression analysis. Hence, we dropped that influential data point from our analysis and finally included 949 observations in the analysis. We took multiple days-samples such as observations during $6^{\text {th }}-7^{\text {th }}$ April, $6^{\text {th }}-8^{\text {th }}$ April, $6^{\text {th }}-9^{\text {th }}$ April.......... $6^{\text {th }}-30^{\text {th }}$ April and ran multiple models on these samples. First, we performed different hypothesis tests to decide the single preferred model for the analysis of each sample data. Fixed effects model and random effects model were tested against pooled OLS regression model by $\mathrm{F}$ test and Breusch-Pagan Lagrange multiplier test respectively. As in each case, the null hypothesis was rejected, we considered fixed effects and random effects model appropriate for the analysis. Then we ran the Hausman test to decide whether fixed effects or random effects model 
should be preferred for the analysis of each sample data and found the fixed effects model suitable in the majority of cases. All the models with favorable model fit statistics were only included and the effect of the independent variables on the outcome variable was examined using an appropriate model with cluster-robust standard errors to allow for heteroscedasticity and serial correlation.

A percentage increase variable was created using the formula: Percent increase $=$ New cases $(t) /$ Cumulative cases ( $t-1)$ where $t$ is daily. This was the outcome variable for our study which was examined for its association with four time-varying independent meteorological variables such as average air temperature, average relative humidity, average air pressure, and average wind speed. In the fixed-effects model (least squares dummy variable model), dummy variables were introduced for every district barring Mumbai (exhaustive dummy variables always need a reference point). This means that observations from a particular district would have a value of 1 in that district dummy and 0 in all other district dummies. The dummy variables capture variance due to factors specific to the district that do not change over time. The fixed-effects model allows us to only look at how inter-day variation in temperature, relative humidity, pressure, and wind speed explain the spread of COVID-19. In this model, we could effectively compare the same districts over time and then compared those results with other districts in the same time period.

In the random-effects model, other time-invariant covariates such as latitude, longitude, malaria annual parasite index, BCG vaccination rate, and Polio vaccination rate along with the abovementioned timevarying meteorological factors were examined. All the analyses were performed using the RStudio version 1.3.959 and SPSS version 21.0 software. The statistical tests were two-tailed, and $p<0.05$ was considered statistically significant.

Ethics approval: This study did not require research ethics approval, as we used publicly accessible, anonymized aggregate data for all analyses.

\section{Results}

We included 38 districts with 949 observations over a period of one month ( $1^{\text {st }}-30^{\text {th }}$ April 2020) in our analyses. Figures 1 and 2 show the presence of heterogeneity across days and districts respectively. Table 1 summarizes the descriptive statistics for COVID-19 confirmed cases and meteorological variables. The study included 20,373 cases during the observation period and average daily confirmed cases were 21.47. Average daily temperature, relative humidity, air pressure, and wind speed were $31.78^{0}$ C, $41.32 \%, 1149.86 \mathrm{hPa}$, and $8.91 \mathrm{~m} / \mathrm{s}$ respectively.

Table 2 shows the correlation coefficients among the meteorological variables. Mean temperature had significant negative correlations with relative humidity $(r=-0.522, p<0.01)$, air pressure $(r=-0.480, p<$ $0.01)$, wind speed $(r=-0.234, p<0.01)$.

As depicted in table 3 , all the fixed effects models consistently revealed that air temperature had a significantly negative impact on COVID-19 cases i.e. on average, every one-degree rise in AT led to a 
decrease in 3.909 points in percent increase in COVID-19 cases. In all the models, ARH was negatively associated with percent increase in COVID-19 cases and the association was statistically significant in models 9-14. None of the models revealed any significant relationship between air pressure and wind speed with percent increase in COVID-19 cases.

In table 4, all the random effects models showed a negative effect of AT and ARH on percent increase in COVID-19 cases although, in most of the models, the association was statistically insignificant. However, we observed that with one unit increase in the malaria annual parasite index, there was a significant increase in 10.835 points (on average) in percent increase in COVID-19 cases. The effect of other variables such as air pressure, wind speed, latitude, longitude, BCG vaccination rate, and Polio vaccination rate on COVID-19 cases was found statistically insignificant.

\section{Discussion}

In this cross-sectional time-series study of 38 districts with 20,373 confirmed cases of COVID-19, percent increase in COVID-19 during the follow-up period from $1^{\text {st }}$ to $30^{\text {th }}$ April 2020, was negatively associated with AT and $\mathrm{ARH}$, but positively associated with the malaria annual parasite index. This cannot be mistaken that high temperature and high humidity will take care of the COVID-19 pandemic as these results only hold under the condition of strict lockdown measures in India. Thus, the intervention measures like limiting population movement, restricting mass gatherings, closure of institutions, social distancing, and other quarantine methods might have an important impact on the associations between the meteorological factors and transmission of the virus.

It is known that the coronavirus is transferred through direct and close contact with respiratory droplets of the affected person or contact with contaminated surfaces (Ghinai et al. 2020; Harmooshi et al. 2020). Our study findings suggest that climatic factors such as air temperature and relative humidity might have a role in the spread of COVID-19 by negatively impacting the transmission and survival of the virus in the environment or on the contaminated surfaces. Consistent with our result, Wang et al. in their study in 105 pairs of the virus carriers and the infected from 100 Chinese cities observed that high temperature and high humidity significantly reduced the transmission of the virus (Wang et al. 2020). Another study conducted in 31 different states of China and 70 cities of 11 countries revealed that air temperature and humidity had a detrimental impact on the transmission of the 2019-new coronavirus (Roy 2020). Similar result has also been supported in other literatures (Guo et al. 2020; Oliveiros et al. 2020; Qi et al. 2020). However, contrasting our results, some studies could not find any evidence supporting the fact that COVID-19 cases could decline in warm, humid regions (Juni et al. 2020; Xie and Zhu 2020). We also observed in our study that percent increase in COVID-19 cases was positively associated with malaria endemicity of districts which indicates that there might be a limited spread of COVID-19 in malaria-free districts as compared to malaria-endemic districts. This is in contrast to the result found in an earlier study (Muneer et al. 2020). Further studies exploring the relationship of malaria endemicity with COVID19 transmission are needed to be conducted to establish such an association. 
Our study has some limitations. First, some potential risk factors such as district-specific general health policies and socioeconomic status which could influence the spread of COVID-19 were not included in the models. Also, we could not consider the district-specific population density in our study as the latest data were not available. Second, our data only covered districts of India and thus the findings may not be generalized to other regions of the world. Third, it is difficult to quantify the compliance of the population with social distancing and other restrictions of lockdown measures.

\section{Conclusion}

Our study shows that meteorological factors like air temperature, relative humidity, and malaria endemicity are associated with the spread of 2019-nCoV. Based on our results and other recent available evidence, it seems that high temperature and relative humidity might play an essential role in the stability and transmissibility of 2019-nCoV. However, we suggest that more rigorous studies should be done with data from other countries using different study designs and incorporating other covariates like population density, health infrastructure, cultural practices etc. to validate these findings.

\section{Declarations}

Funding: No funds, grants, or other support was received.

Conflicts of interest: The authors have no conflicts of interest to declare that are relevant to the content of this article.

Ethics approval: Not applicable

Consent to participate: Not applicable

Consent for publication: Not applicable

Availability of data and material: Data were retrieved from appropriate publicly accessible websites.

Code availability: Not applicable

\section{References}

Chan JFW, Yuan S, Kok KH, et al (2020) A familial cluster of pneumonia associated with the 2019 novel coronavirus indicating person-to-person transmission: a study of a family cluster. Lancet 395:514-523. https://doi.org/10.1016/S0140-6736(20)30154-9

Chen H, Guo J, Wang C, et al (2020) Clinical characteristics and intrauterine vertical transmission potential of COVID-19 infection in nine pregnant women: a retrospective review of medical records. 
Lancet 395:809-815. https://doi.org/10.1016/S0140-6736(20)30360-3

Ghinai I, McPherson TD, Hunter JC, et al (2020) First known person-to-person transmission of severe acute respiratory syndrome coronavirus 2 (SARS-CoV-2) in the USA. Lancet 395:1137-1144. https://doi.org/10.1016/S0140-6736(20)30607-3

Guo X-J, Zhang H, Zeng Y-P (2020) Transmissibility of COVID-19 and its association with temperature and humidity. https://doi.org/10.21203/rs.3.rs-17715/v1

Gupta D (2020) Effect of Ambient Temperature on COVID 19 Infection Rate. Preprint

Harmooshi NN, Shirbandi K, Rahim F (2020) Environmental Concern Regarding the Effect of Humidity and Temperature on SARS-COV-2 (COVID-19) Survival: Fact or Fiction. Environ Sci Pollut Res. https://doi.org/10.2139/ssrn.3563403

Juni P, Rothenbühler M, Bobos P, et al (2020) Impact of climate and public health interventions on the COVID-19 pandemic: A prospective cohort study. Can Med Assoc J 192:E566-E573.

https://doi.org/10.1503/cmaj.200920

Lai CC, Shih TP, Ko WC, et al (2020) Severe acute respiratory syndrome coronavirus 2 (SARS-CoV-2) and coronavirus disease-2019 (COVID-19): The epidemic and the challenges. Int J Antimicrob Agents 55:105924. https://doi.org/10.1016/j.ijantimicag.2020.105924

Lauer SA, Grantz KH, Bi Q, et al (2020) The Incubation Period of Coronavirus Disease 2019 (COVID-19) From Publicly Reported Confirmed Cases: Estimation and Application. Ann Inetrnal Med

Li Q, Guan X, Wu P, et al (2020) Early transmission dynamics in Wuhan, China, of novel coronavirusinfected pneumonia. N Engl J Med 382:1199-1207. https://doi.org/10.1056/NEJMoa2001316

Muneer A, Kumari K, Tripathi M, et al (2020) Comparative analyses revealed reduced spread of COVID-19 in malaria endemic countries. medRxiv-preprint 2020.05.11.20097923.

https://doi.org/10.1101/2020.05.11.20097923

Oliveiros B, Caramelo L, Ferreira N, Caramelo F (2020) Role of temperature and humidity in the modulation of the doubling time of COVID-19 cases. medRxiv-preprint.

https://doi.org/10.1101/2020.03.05.20031872

Qi H, Xiao S, Shi R, et al (2020) COVID-19 transmission in Mainland China is associated with temperature and humidity: A time-series analysis. Sci Total Environ 728:138778.

https://doi.org/10.1016/j.scitotenv.2020.138778

Roy I (2020) Combating recent pandemic of COVID-19 - An urgent Solution. Preprints. https://doi.org/10.20944/preprints202003.0366.v1 
Sohrabi C, Alsafi Z, O'Neill N, et al (2020) World Health Organization declares global emergency: A review of the 2019 novel coronavirus (COVID-19). Int J Surg 76:71-76.

https://doi.org/10.1016/j.ijsu.2020.02.034

Wang J, Tang K, Feng K, Lv W (2020) High Temperature and High Humidity Reduce the Transmission of COVID-19. Preprint. https://doi.org/10.2139/ssrn.3551767

Xie J, Zhu Y (2020) Association between ambient temperature and COVID-19 infection in 122 cities from China. Sci Total Environ 724:138201. https://doi.org/10.1016/j.scitotenv.2020.138201

Xu Z, Shi L, Wang Y, et al (2020) Pathological findings of COVID-19 associated with acute respiratory distress syndrome. Lancet Respir Med 8:420-422. https://doi.org/10.1016/S2213-2600(20)30076-X

\section{Tables}

Due to technical limitations, full-text HTML conversion of Tables 1-4 could not be completed. However, they can be downloaded and accessed in the Supplementary Files.

\section{Figures}


Heterogeineity across days

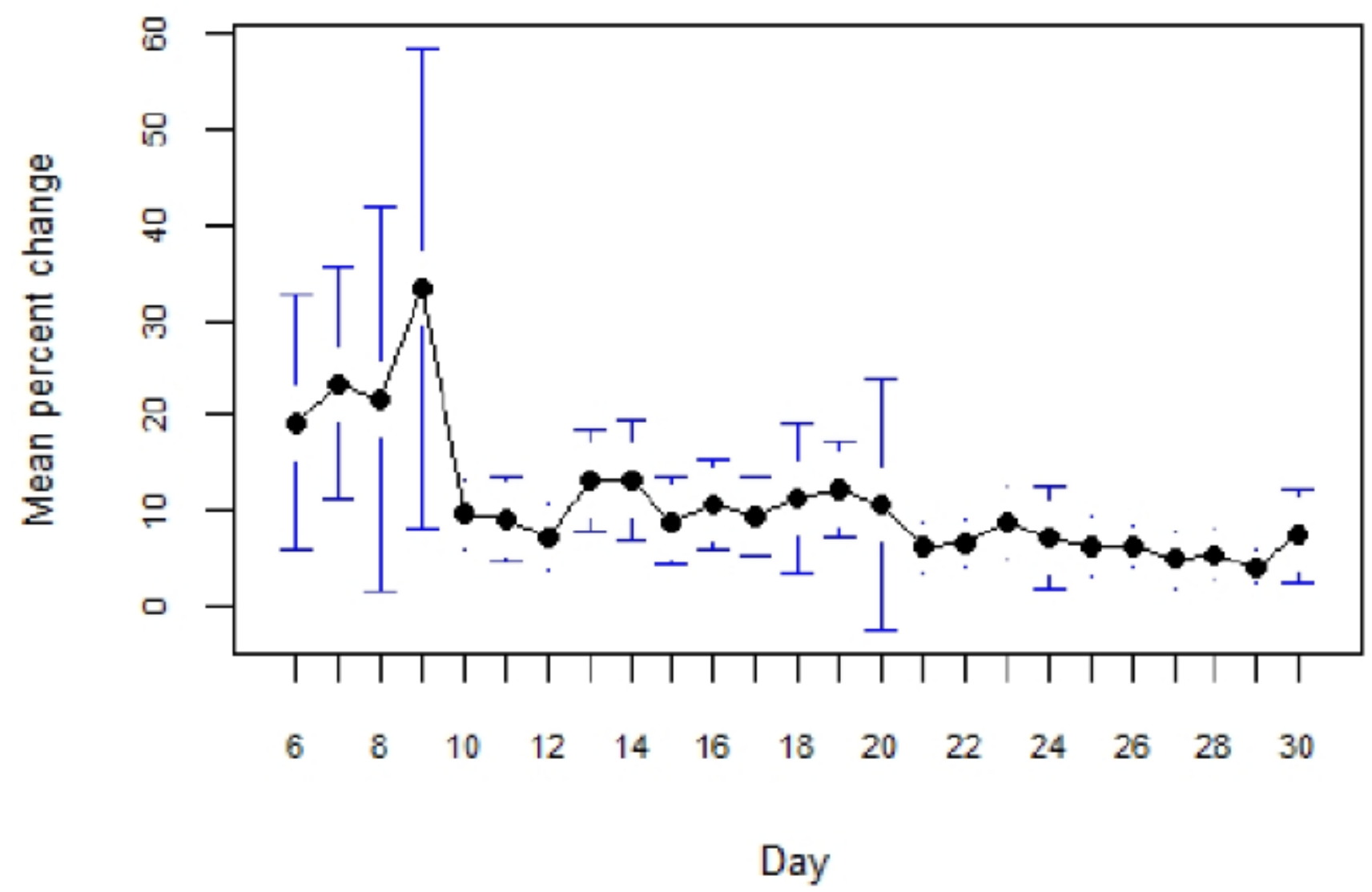

Figure 1

Mean percentage change (with 95\% confidence interval) in COVID-19 cases across days in the month of April 2020 in selected districts of India 


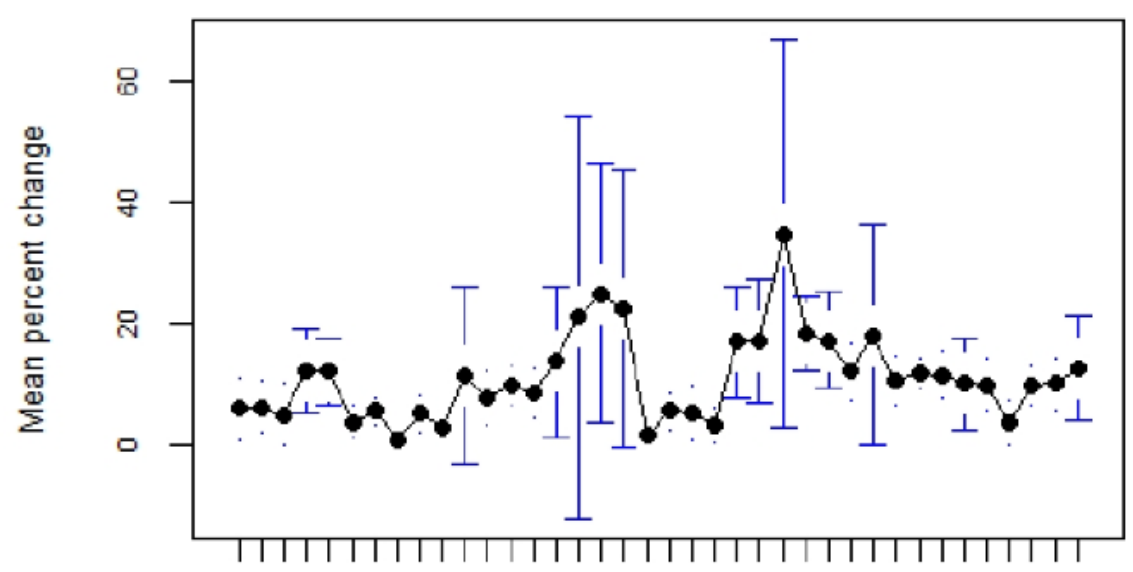

$\begin{array}{lllllllllllllll}1 & 3 & 5 & 7 & 9 & 11 & 14 & 17 & 20 & 23 & 26 & 29 & 32 & 35 & 38\end{array}$

District

2020

Note: Numbers on $\mathrm{x}$-axis denote the following districts selected for the study:

1-South Andaman, 2-Chandigarh, 3-Gurugram, 4-Bandipore, 5-Jalandhar, 6-Srinagar, 7- Bangalore, 8-Kasaragod, 9-Mysore, 10-Kannur, 11-Mewat, 12Sahibzada Ajit Singh Nag, 13-Guntur, 14-Kurnool, 15-Munger, 16-Korba, 17-Ranchi, 18-Jajapur, 19-Khordha, 20-Hyderabad, 21 - Nizamabad, 22-Dehradun, 23-Kolkata, 24-North Twenty Four Parganas, 25-New Delhi, 26-Ahmadabad, 27-Surat, 28-Jodhpur, 29-Bhopal, 30-Indore, 31-Mumbai, 32-Pune, 33-Central Delhi, 34-Jaipur, 35- Coimbatore, 36-Chennai, 37-Agra, 38-Lucknow

\section{Figure 2}

Mean percentage change (with 95\% confidence interval) in COVID-19 cases across selected districts of India in the month of April

\section{Supplementary Files}

This is a list of supplementary files associated with this preprint. Click to download.

- Table1.jpg

- Table2.jpg

- Table3.jpg

- Table4.jpg 